ISSN: 2162-3104 Print/ ISSN: 2166-3750 Online

Volume 8, Issue 2 (2018), pp. 696-723

(C) Journal of International Students

http://jistudents.org/

doi: 10.5281/zenodo. 1250372

\title{
Experiences of International Student-Athletes at a Historically Black University
}

\author{
Takahiro Sato \\ Kent State University, USA \\ Samuel R. Hodge \\ The Ohio State University, USA \\ Kevin Eckert \\ Kent State University, USA
}

\begin{abstract}
The purpose of the study was to scrutinize and explain the academic, social, and athletic experiences of international student-athletes attending a historically Black university. Participants were six international studentathletes (five men and one woman). Situated in position theory, the research design was explanatory multiple case study. The primary data collection method was semi-structured interviews. The interviews were analyzed using a constant comparative approach and revealed that the participants were positioned by language differences and academic difficulties, were disengaged from some teammates, and endured athletic disadvantages in resources and training. To amply support international student-athletes, we assert that athletic departments, coaches, faculty, and students should respect and value the identities, as well as the linguistic and cultural backgrounds of international student-athletes.
\end{abstract}

Keywords: Athletics, International student-athletes, Language differences, Low resource institutions, Positioning, Historically black university 


\section{INTRODUCTION}

The athletic, academic, and social experiences of international studentathletes are often distinctive and unique, particularly for those matriculating at Historically Black Colleges and Universities (HBCUs) in the United States (U.S.) of America (Sato, Hodge, \& Burge-Hall, 2011). The Higher Education Act of 1965 defines Historically Black Colleges and Universities (HBCUs) as institutions of higher education established before 1964 whose principal mission was then, and remains today, the education of Black Americans (Hodge, 2015; Wilson, 2007). International student-athletes at times find it difficult to meet academic standards or follow the guidelines established by the National Collegiate Athletic Association (NCAA) to enter college (Connell, 2007), or they may struggle to maintain certain grade point average (GPA) levels regulated by the NCAA to maintain athletic eligibility as a collegiate athlete (NCAA, 2007). These student-athletes may become worried about possibly losing their athletic scholarships; which in-turn, would lead to possible separation from their athletic teams or even the institution (Sato et al., 2011). The challenges for student-athletes who have international status occur in the salient areas of academic performance, social adjustment, and institutional factors which may contribute to negative experiences including exclusion or racism (Sato et al., 2011).

\section{LITERATURE REVIEW}

Sato et al. (2011) analyzed the academic, athletic, and social experiences of international student-athletes from Brazil, Serbia, South Korea, and the Philippines who were members of athletic teams at a HBCU in the U.S. The international student-athletes believed language differences led to academic, athletic, and social difficulties. Further, Sato and colleagues reported that the student-athletes mostly felt marginalized. These factors had negative effects on the value of their experiences at the HBCU. A counter narrative (finding) was that some African American peers and faculty were empathetic and supportive of the international student-athletes (Sato et al., 2011).

There are a number of studies focused on the experiences of international students in the general student body at colleges and universities in the U.S. (Hayes \& Lin, 1994; Sato \& Hodge, 2009; Wan, 2001) as well as studies on international student-athletes at predominantly White degreegranting institutions (Ridinger \& Pastore, 2000). Degree-granting 
institutions are "defined as postsecondary institutions that grant associates or higher degrees and participate in Title IV federal financial aid programs" (Snyder, Dillow, \& Hoffman, 2009, p. 3). Some of the findings are quite troubling. For example, Sato and Hodge (2009) reported that Asian international graduate students have experienced feeling marginalized, alienated, isolated, discriminated against, and even targets of racism. Further such students may have communication difficulties caused by a lack of English proficiency (Sato \& Hodge, 2009; Wan, 2001). International students have voiced concerns about various challenges such as adapting to new roles, academic and language difficulties, financial issues, and homesickness (Barrett \& Huba, 1994; Hayes \& Lin, 1994; Parr, Bradley, \& Bingi, 1992; Sato \& Hodge, 2016). Despite the increased presence of international student-athletes on HBCU campuses, the extant research-base is underdeveloped on their academic, social, and athletic experiences at such historic institutions (Sato et al., 2011). There is need to study the experiences of international student-athletes using research methodologies which are theoretically-grounded.

\section{CONCEPTUAL FRAMEWORK AND PURPOSE}

This study was situated in the positioning theory of social behavior, which explains the fluid patterns of dynamic and changing assignments of rights and duties among groups of social actors (Varela \& Harré, 1996). The term positioning means to analyze interpersonal encounters from a discursive viewpoint (Hollway, 1984). Davies and Harré (1990) asserted that when an individual assumes "a particular position as one's own" (p. 46), that individual "inevitably sees the world from the vantage point of that position and in terms of the particular images, metaphors, story lines, and concepts which are made relevant within the particular discursive practice in which they are positioned" (p. 46). Mindful of this logic, we examined the academic, social, and athletic experiences of international student-athletes on a HBCU campus. Positioning theory helps us better understand and explain what international student-athletes experience based on their academic, social, and athletic experiences at an HBCU-experiences that influence their thoughts, feelings, and beliefs about interacting with teammates, coaches, and faculty.

One tenet of positioning theory is intentional self-positioning, which incorporates both a conceptual repertoire and a location for persons within 
the structure of rights and duties (Yoon, 2008). Hermans (2001) identified two factors that affect a person's position, which were (a) internal and (b) external factors of self-positioning. An internal factor means a position within the inner group that the person feels a part of (e.g., as a studentathlete, as a foreigner). An external factor refers to a position within the outer group (e.g., in relation to my teammates, classmates, or coaches). Both internal and external factors mutually influence a person's self-positions, because they are part of a self that is intrinsically or extrinsically extended to the group environment and culture that respond to individual experiences in the environment that is perceived as 'mine' (Hermans, 2001). Self-positions reflect the complex shifts between internal and external factors that help to describe a person's learning, social behaviors, and challenges (Hermans, 2001).

Davies and Harré (1990) use the term "reflective positioning," which is useful in explaining how international student-athletes position their own roles as both students and athletes. The term "reflexivity" might refer to how international student-athletes critically monitor and understand their academic and athletic roles. Reflective position is closely related to the personal interpretative framework (in particular, academic and/or athletic success) or the normative assumption about good student behaviors that are the basis on which individuals ground their decisions for actions in particular situations (Vanassche \& Kelchtermans, 2014).

Student-athletes' reflective positions would likely shape how they participate in academic, social, and athletic discourses, as they must combine and negotiate different positions (e.g., roles as athletes, students, friends) (Jones, 1997). Although they might consciously understand that they play various roles when studying or communicating with classmates, teammates, and faculty, they might be unintentionally positioned within their classes or teams as powerless or oppressed in isolated spaces, which can lead to negative consequences such as marginalization (Yoon, 2008). Jones (1997) explained it was important for individuals to analyze and reflect on their own disposition as opposed to or aligned with positioning by others. The reflexivity of student-athletes might be defined by "indexing one's statements with the point of view one has on its relevant world" (Harré \& van Langenhove, 1999, p. 62). This means that student-athletes' experiences and backgrounds influence their positioning (beliefs, thoughts, judgments) and, in turn, their actions in learning (Yoon, 2008). 
Further interactive positioning is "how one person positions another" (Davies \& Harré, 1990, p. 48). How student-athletes are positioned limits or extends what they can exhibit or provide in choice of speaking forms and actions (Harré \& van Langenhove, 1999). Interactive positioning helps to identify student-athletes' self- and other discourses based on interaction among the student-athletes themselves and with classmates, coaches, teammates, and others. Andreouli (2010) asserted that an interactive position emphasizes the other as an integral part of the positioning process. Individuals jointly (re)produce relational meanings so that they may see the world from one point of the position, such as metaphors, storylines, and concepts that may or may not be relevant to others within the self-other discourse. The concept of interactive positioning suggests that student-athletes' experiences or interactions may positively or negatively influence the academic and social positions of others. Interactive positioning also helps to identify political or hierarchical interactions among conflicting values or norms on the part of faculty, coaches, and studentathletes. A faculty member or coach might reject or accept student-athletes on campus (Harré \& Moghaddam, 2003).

We judged positioning theory as a useful lens for examining how student-athletes position themselves and are positioned in athletic and educational contexts. The purpose of this study was to analyze and explain the academic, social, and athletic experiences of international studentathletes at a historically Black university. The central research question was: What meaning do international student-athletes ascribe to their academic, social, and athletic experiences while matriculating at a HBCU?

\section{RESEARCH METHOD}

\section{Research Design}

For this study, we used an explanatory (holistic) multiple case study design, which allowed us to conduct each case as a separate study and to reflect replication logic (Yin, 2003). In this study, replication logic was situated in the framework of positioning theory (Davies \& Harré, 1990) to better understand the conditions in which a particular phenomenon (e.g., athletic, academic, and social experiences) was likely to be found (i.e., literal replication predicts similar results across cases), as well as the conditions where it was not likely to be found (i.e., theoretical replication predicts contrasting results but for predictable reasons) (Yin, 2003). We 
used this approach to explore the complexities of international studentathletes' experiences on a HBCU campus replicated across cases.

Table 1. International Student-Athletes' Demographic Data

\begin{tabular}{|c|c|c|c|c|}
\hline Pseudonym & $\begin{array}{c}\text { Academic } \\
\text { Major }\end{array}$ & Gender & Language & Ethnicity/Race \\
\hline Bob & Recreation & Male & Korean & Korean \\
\hline Jess & Journalism & Female & Tagalog/English & $\begin{array}{l}\text { Malayo- } \\
\text { Polynesian }\end{array}$ \\
\hline Greg & Business & Male & Serbian & Slavonian \\
\hline Mark & $\begin{array}{l}\text { Health and } \\
\text { Physical } \\
\text { Education }\end{array}$ & Male & Portuguese & $\begin{array}{l}\text { Two or more } \\
\text { races: Native } \\
\text { Brazilian- } \\
\text { Japanese and } \\
\text { White }\end{array}$ \\
\hline Nemo & Business & Male & Portuguese & $\begin{array}{l}\text { Two or more } \\
\text { races: Native } \\
\text { Brazilian- } \\
\text { Japanese and } \\
\text { White }\end{array}$ \\
\hline Calvin & Recreation & Male & English & $\begin{array}{l}\text { Two or more } \\
\text { races: White and } \\
\text { Hispanic }\end{array}$ \\
\hline
\end{tabular}

Note . Language $=$ Native (primary) language.

\section{Research Site and Sampling}

The research site was a private HBCU with an enrollment of some 4,500 students. This university had NCAA Division I-AA4 affiliation - the moderate level of competition in intercollegiate athletics. The NCAA's Football Championship Subdivision (FCS) was formerly called Division 1AA. The selection of case study participants involved contacting the athletic department at the HBCU and seeking nominations of international studentathletes matching the selection criteria (Yin, 2003). The maximum variation sampling (Patton, 2002) criteria were: (a) held international status, (b) had an athletic scholarship, and (c) maintained academic eligibility to participate in athletic activities. During the conduct of this study, there were some 250 student-athletes enrolled at the HBCU. Fifteen potential participants from the athletic department were nominated for this study. 


\section{Participants}

The participants were six international student-athletes who volunteered to participant in this study. These participants were Jess, a student of Asian heritage who was originally from Mindanao, The Philippines. There was also Mark and Nemo both from Sao Paulo, Brazil as well as Bob, Greg, and Calvin from Seoul, South Korea; Belgrade, Servia; and Ontario, Canada, respectively. Pseudonyms were used for all participants. In this paper, we operationally define international students as those who declared themselves as non-immigrant to the host country (Sato \& Hodge, 2016). Table 1 presents the participants' demography.

\section{Data Collection}

The data collection methods involved conducting face-to-face semistructured interviews with each participant and securing a copy of the academic programs of study from each participant. Before conducting the study, approval was sought and received from the lead researcher's institution's Behavioral Sciences Institutional Review Board.

\section{Semi-Structured Interviews}

Each participant was interviewed following a semi-structured interview approach during both in-season and off-season (Yin, 2003). Specifically, the lead researcher used a protocol consisting of a 15-question in-season interview guide and an 8-question off-season interview guide about student-athletes' experiences (NCAA, 2007; Sato et al., 2011). Mostly, the questions solicited information on the participants' views about people, places, and events related to their academic, social, and athletic experiences at the HBCU (Yin, 2003). The interviews took on a conversational style guided by a pre-established set of questions that were originally developed by NCAA (2007) and modified by Sato et al. (2011). The specific questions were modified and carefully worded for relevance to the current investigation of international student-athletes in undergraduate programs at a HBCU. For example, some questions involved the studentathletes' athletic and academic performance, diversity, retention, recruitment, and factors associated with the successful completion of undergraduate degrees (NCAA, 2007).

The participants were interviewed, face-to-face, on the HBCU's campus and the interviews typically lasted between 60 and 90 -minutes. The interviews were conducted with each participant during the respective in- 
and off-seasons. Because softball, tennis, track and field, and football seasons are scheduled differently, each interview was held in-line with the respective seasons. Follow-up questions typically to clarify participants' comments were asked via telephone (Shuy, 2002) and e-mail (Meho, 2006), as warranted. After this process was complete, the researchers transcribed the interviews and returned all transcribed data to all participants for member checking (Lincoln \& Guba, 1985; Patton, 2002) via e-mail (Meho, 2006). This process was used to ensure the transcribed data accurately represented the participants' views and experiences at the HBCU.

\section{Trustworthiness and Data Analysis}

Trustworthiness in this study was established through triangulation, member checking, and peer debriefing. Triangulation involved the use of multiple perspectives, including data from interviews, all of which were interpreted through the lens of positioning theory. Use of triangulation is intended to evaluate the accuracy of the data, as opposed to seeking universal truth (Merriam, 1998). First, member checking was used to reduce the impact of subjective bias (Patton, 2002). The lead researcher e-mailed a copy of the transcribed interview data to the individual participants. The participants' acknowledgment of the accuracy of the data and the researchers' interpretations of the data ensured that trustworthiness was established (Merriam, 1998). Second, the peer debriefers were two wellestablished qualitative researchers with expertise in this area of inquiry. They judged the interpretations of the data as accurate and representative of the participants' statements.

A constant comparative method (Boeije, 2010) was used to interpret the data. The basic strategy of this analytical process is to relentlessly compare different pieces of data. More specifically, each potentially meaningful piece of data within the transcripts from the first set of interviews with each participant, as well as their interview transcripts from the in- and off-season interviews, were coded independently by the first and second researchers, and any differences were discussed until agreement was reached. The second set of interviews about practice experiences were initially coded by the lead researcher and then checked by the second researcher. In addition, the two peer de-briefers reviewed the codes to avoid potential researcher bias. The coded data from three sets of transcripts from each participant were compared so as to identify similarities and differences. 
After peer debriefing, the researchers conducted a second round of coding key terms (e.g., positions; academic, social, and athletic experiences; motivation; campus culture; and athletic contributions) in the transcripts of the data sources (recoding the original ones). During this process, some codes were combined (e.g., the similar terms interaction and experiences), while others were split into subcategories (subthemes).

Finally, the researchers examined the final codes to organize them into a hierarchical structure using individual and group coding percentages (how many times key terms appeared in the data source). Then all data and the definitions of the key terms were sent back to all participants for a second round of member checking. After receiving final confirmation from all participants, the researchers grouped the codes into thematic categories, which were then refined into recurring themes (Boeije, 2010).

\section{RESULTS}

Three salient themes emerged from our analyses of the data. These themes were: (a) differences and difficulties, (b) social disengagement, and (c) under-resourced. These salient themes influenced the academic, social, and athletic experiences of international student-athletes at the HBCU. The themes and subthemes are discussed in the following narrative, with supporting quotes from the participants.

\section{Differences and Difficulties}

This theme exposes the academic difficulties often attributed to language differences (speaking and writing) as experienced by the participants at the HBCU. They struggled to earn passing grades on their writing assignments, as they grappled with cultural and fluency discrepancies in the daily use of the English language. They often misunderstood theoretical concepts and the content of class lectures. This made them feel more challenged and excluded, especially because their cultures, traditions, and in cases their languages were outside the dominant culture of their academic setting.

Intensifying their academic struggles, the participants shared similar experiences in that they perceived comments from some of their professors to be negative and reflective of stereotypic beliefs about their positioning as student-athletes of diversity. Many professors demonstrated a concern about the student-athletes' class behaviors and dedication to academic studies, 
believing that student-athletes prioritized athletic activities over their education. Additionally, the participants held the belief that some faculty assumed that their native backgrounds also influenced their academic competence and motivation, so that their efforts would not be enough to succeed in the courses.

\section{Subtheme I: Additional Effort}

The student-athletes believed that cultural and linguistic differences caused them to struggle to write papers and meet the academic standards required by their professors. They had limited fluency writing and speaking using the English language. The student-athletes, even those from Englishspeaking countries such as Calvin from Canada and Jess, who had lived in the U.S. since she was 11-years old, were advised to get additional help and support from academic services (e.g., writing center or counseling services) through the athletic department and/or the university. What is more, the student-athletes who used English as a second language had speaking difficulties, which were reflected in class participation and presentations. They realized that their professors wanted to treat the international and American students on the same footing. It seems that some professors wanted to help student-athletes, but assumed that the student-athletes' competence in speaking and writing proficiently in English, as well as their reading and comprehension abilities, were not good enough to succeed in their courses. In an interview, Calvin (a Canadian football player) explained his academic experiences as follows:

I speak English. The only problem that I had was to write papers. We write some words different, like sentence construction, words. I had English 101. I got bad test scores. I talked to the teacher and I told him I needed more help for my writing from a tutor. I have a computer from back home. The computer tells me everything was right, but when I turn it in, teachers put comments about poor grammar and spelling. First, when I came here I did not understand African American slang or expression, and I had a hard time understanding their words. I understood 50\% but not fully. I decided to visit the writing center to learn and read the papers that are relevant to the African American culture in this university (Calvin, interview). 
Calvin felt that his professor for the Introduction to College Writing (English 101) course positioned him as an unaccepted student in the classroom. Calvin mentioned that "my professor ignored my academic background and experiences in my home country". This was a common experience among the student-athletes, even those from English-speaking countries. Greg, a student-athlete from Serbia, also had writing issues and concerns, and at the same time, he struggled to speak English proficiently. Greg's academic counselor in the department of athletics did not offer a conversation partner program or any other opportunity that would help him to improve his English proficiency. When interviewed, Greg shared his concerns about speaking:

I need to ask [for] academic help or support from classmates and professors. The hardest classes I have taken were sociology and psychology. I had to speak a lot. I had to practice rehearsals of presentations before my presentation to the class. I am struggling with speaking and presenting during the class time - they are the hardest assignments. I had to visit the professors during their office hours. You need to have presentation skills. I am always nervous when I do a presentation. I had already one group presentation which was a nightmare, but I do not know how I am going do if I have individual presentation assignment in future. I put in extra efforts, but I have not satisfied my academic experiences (Greg, interview).

Greg positioned himself as powerless and academically inferior in situations where he was required to present in front of classmates.

\section{Subtheme II: Interaction with Faculty}

All six participants mentioned similar experiences in that they perceived stereotypical or offensive comments from professors who taught general requirement core courses. Many professors were concerned about the student-athletes' dedication (or perceived lack of) to their studies and reminded them that they would not treat student-athletes differently from their other students. The student-athletes believed these faculty assumed that their academic motivation and efforts would not be good enough to perform successfully in their courses. The participants were certain that their professors had negative sport and race-based stereotypic images of student- 
athletes on campus. They all attempted to meet all the requirements set by the professors, but it was time-consuming and challenging. They were motivated to earn good final grades; in-part, because they wanted to provide better images of student-athletes.

Nemo, a tennis player, was required to take an African American history course as a general core course. He felt his professor positioned him in uncomfortable situations and discriminated against him in class. He shared his experience during an interview:

Faculty members ... most of them are pretty good. I have one from African American History class. Since I go to an $H B C U$, the class is one of general requirements of my curriculum. Once every week, she (the professor) says racist things of White people, even Asian people. She says certain things that did not make me comfortable. Every classmate looked at me like I am different. I feel discriminated by her behaviors. She knows I am Brazilian, and I am not White American. They think that I have similar skin color with White Americans, and they treated me negatively. It made me feel uncomfortable. (Nemo, interview)

In an effort to assist these student-athletes, their academic counselors encouraged them to enroll in online courses rather than classroom-based courses. They discussed their online course experiences. The student-athletes felt they were treated equally by instructors in their online courses in their on-line interactions.

\section{Social Disengagement}

This theme indicates that all six participants had negative social experiences, which were disengaging for them, such as racism or lack of peer support with teammates on their athletic teams. They believed that some of their teammates disrespected the different racial backgrounds of the participants. The participants felt that some teammates had not been exposed to interacting with international student-athletes or persons of color in their hometowns or local neighborhood schools. Some teammates were disengaging, perhaps because they did not know how to welcome foreignborn students as their teammates. The international student-athletes felt that geographical location had significantly affected and shaped their patterns of social engagements on athletic teams. Additionally, their teammates (re)produced stereotypical racial views and behaviors toward international 
student-athletes. The participants admitted that they had limited contextspecific knowledge about how best to position themselves as international student-athletes on the HBCU campus.

\section{Subtheme I: Lack of Peer Support from Teammates}

The participants expressed a desire to have good role models or mentors in teammates. Many of them were first-generation college students, so they had no idea of how to meet athletic and academic expectations from their coaches and professors. Common across cases, Greg did not have a mentor while he was playing tennis at the HBCU. Additionally, he felt that there was no teamwork and there was a lack of motivation within the team. He was completely dissatisfied, and he explained how he felt the tennis team was dysfunctional:

Unfortunately, I see negative perspectives of peer support.
Specifically, with tennis, the coaching staff and peers do not
motivate us. We do not have a captain of the team, and there is
no leadership or mentor roles. I do not want to say negative
things about this team, but as an athlete, if you want to function
as a team together, we need a captain and mentor who
contribute to team building and support system as a team. In
some practices, we have some teams who do not want to be
serious, because some of my teammates focus on academics
rather than athletics. Many teammates are international
student-athletes and it is difficult to maintain their GPA. If they
do not keep their academic eligibility, they may be expelled
from this university and leave this country. (Greg, Interview)

Greg felt that all of his teammates were losing their athletic motivation. The tennis teammates (Mark, Bob, and Nemo) heavily prioritized their studies over athletics, which created friction with their teammates. Greg believed that student-athletes could not care about their team and athletics as much as their studies because they had to maintain a minimum GPA as stipulated by NCAA in order to participate in intercollegiate athletics.

\section{Subtheme II: Racial Discrimination}

All six participants felt a sense of detachment, exclusion, and/or separation. They experienced teasing by teammates and other studentathletes that they interpreted as racial discrimination. For example, Mark, 
Nemo and Greg had heard negative comments about themselves made by several Black student-athletes. They felt that international student-athletes who had a lighter skin color were treated unfavorably as White Americans, even though they were not born and raised in the U.S. Mark, a native Brazilian, who was bi-racial, explained:

I am Brazilian, but I considered myself as white student. Many female students come and talk to me friendly. Male students, that is hard. Some female students like White guys, because we are different. I was having dinner with other Brazilian teammates. One female athlete from Track Team sat right next to me. Other male teammates from Track team told her that "Oh, you are sitting with White guys." I told him "what do you mean by that"? He told me "nothing". I feel so isolated on campus. (Mark, interview)

Mark felt that this was the first time he experienced racial discrimination and was offended by other student-athletes. He was hurt and disappointed and was positioned as an outsider and an unwelcome student at the HBCU.

Similarly, Bob and Jess, who were Asian international students, were viewed differently by some students on campus and were teased about the cultural orientation (hierarchical relationships) among Asian studentathletes. Bob was also teased about the cultural behaviors and patterns of his Asian culture by some Black student-athletes. Korean student-athletes develop hierarchical and authoritarian relationships within the group. Some of the African American student-athletes who had observed this group orientation thought it strange and began to tease the Asian student-athletes. Bob said:

It was difficult to accept cultural differences. African Americans highly value group orientation. I am Korean. I do the same, but we also have hierarchical relationships within the groups. African American students told me, 'Koreans have weird and strange group orientations. Is that Asian thing?' They started to generalize and discriminate. Asian and African Americans are so similar, but different. I need to accept differences and avoid discrimination. I get mad for their behaviors sometimes. (Bob, interview) 


\section{Under-Resourced}

Jess, Bob, Mark, Nemo, and Calvin mentioned that their athletic department was situated at a HBCU which was considered a low-resource institution. In this study, the budgetary constraints adversely impacted the athletic department; and in-turn, the athletic teams, coaches and staff, and student-athletes. Eventually, these issues trickled down and negatively affected the athletic motivation of the student-athletes. All coaches except the football and basketball coaches at the institution were required to teach activities or lecture courses as a part of their salary contract, in addition to their coaching service requirements.

\section{Subtheme I: Motivation}

The six participants were less motivated to compete alongside their athletic teams. They were far more concerned about their studies, because they were worried about losing their eligibility and being dismissed from the university (non-immigrant law-violation of student visa). Additionally, coaches and staff at the HBCU had extra duties and tasks such as teaching and service assignments, which interfered with the amount of time they spent monitoring, training, and interacting with their student-athletes. The lack of time and attention dedicated to the student-athletes because of these extra responsibilities and challenges reduced athlete motivation and created friction among teammates.

My coaches are professors or graduate students here. They teach 4 courses during the semester. Then, they're on committees. The only two coaches who do not teach on campus are the football and basketball coaches. Other coaches need to teach physical activity classes and lecture courses. Of course, coaches cannot monitor athletic teams well because this $H B C U$ assigned coaches too many other responsibilities. That is why there are many lazy student-athletes here, because the coaches can't monitor them. We are losing our motivation. (Nemo, interview)

\section{Subtheme II: Underfunded}

The participants had a significant lack of resources and severely underfunded travel budgets, which caused them a great deal of difficulties and at times overwhelmed them. For example, they often had to share hotel 
rooms with more than three or four student-athletes during trips, which made studying and resting extremely difficult. These student-athletes felt that the lack of resources and budgetary limitations of their athletic department placed them in problematic situations that adversely affected their athletic and academic performance. Jess, an Asian international student-athlete, discussed such issues.

I know they put enough money up to travel the football and basketball teams such as staying hotels, coming back a couple of days later. Then when you look at tennis, we have to go on a five-day trip, we go to North Carolina and come back 12:30 midnight. Wake up next day, we do not even eat breakfast, and then play somewhere else like South Carolina, and go to Delaware next day. For five days, we never stayed at hotels, and we ate just two times a day. We are so stressed out and exhausted playing tennis, because we did not have enough money to stay at a hotel. (Jess, interview)

The underwhelmed athletic resources of the HBCU negatively affected the athletic experiences of student-athletes.

\section{DISCUSSION AND CONCLUSIONS}

The international student-athletes gave meaning to differences and difficulties, social disengagement, and the under-resourced athletic program on the HBCU campus. More specifically, the participants were positioned by language differences, which exacerbated their academic difficulties. What's more, the international student-athletes were disengaged from some teammates and endured athletic disadvantages in resources and training. Their struggles had much to do with language and cultural differences and they were academically underprepared, which adversely impacted relationships with faculty, teammates, classmates, and coaches. Common among the student-athletes, they faced difficulty in the proper use of the English language, even though two of them used English as their first language. They experienced such difficulties while matriculating throughout their academic career in the HBCU educational system. The student-athletes were advised by course instructors to seek help from the HBCU's writing center. 
In the logic of positioning theory, when faculty are aware of the contexts from which student-athletes come, they can draw upon their background knowledge to help position them for success by developing academic skills [writing, speaking, and reading] through writing centers, study tables, and mentoring, as examples (McVee, Baldassarre, \& Bailey, 2004). In positioning theory logic, faculty may or may not offer guidance that will position student-athletes for academic success. In this study, the course instructors were attempting to help position the international students for academic and social success. However, such help was overshadowed by forcing the international students to find their own positions by suggesting to them to reflect and assess whether their behaviors align with the instructor's own cultural values. Harré and van Langenhove (1999) asserted that the international students should receive appropriate and culturally relevant mentoring with academic and social support from professors and athletic program staff who reflect a broader spectrum of diversity (as cited in Yoon, 2008, p. 496).

Additionally, positioning theory explains that "being positioned, or position oneself in a certain manner carries obligations and expectations about how one should behave or constrains on what one may meaningfully say or do" (Barnes, 2004, p. 2). The way teammates position international students in an athletic setting is important. Their positioning affects the nature of international students' interactions and their access of learning opportunity as well as social and athletic experiences at the HBCU. Interactive positioning occurs in the moment of academic, social, and athletic interaction, but it is also contextually tied across interaction or scale of study abroad experiences (Kayi-Aydar, 2013). These international student-athletes created new self-positioning that results from the combination of cultural changes of past and current athletic experiences. When international student-athletes experience in one culture, and then migrate to new culture (e.g., joining in HBCU athletic teams), they arrive in a situation in which two or more heterogeneous positions interact with heterogeneous external positions (e.g., policy, practices, schedule, rules, and regulations of $\mathrm{HBCU}$ athletic teams). In some cases, such new selfpositioning may cause internal conflicts between imaginary and actual athletic experiences in different countries and at HBCU.

The study's findings expose the student-athletes' frustration and feelings that some course instructors held stereotypical views about race and/or student-athletes (e.g., 'dumb-jock myths). The student-athletes 
perceived that their professors were concerned about the implementation of culturally inclusive teaching, including the lack of educational training in working with international student-athletes, lack of skills to teach students of diverse backgrounds, lack of appropriate infrastructure, and the lack of adapted curricula in the classroom (Andrews \& Frankel, 2010). Therefore, this current study's results indicate that these student-athletes had difficulty adjusting to academic and behavioral norms in the classroom. For example, some international student-athletes were treated as troublemakers (showing academic laziness) by their professors. Such positions may cause cultural conflicts that international student-athletes need to navigate new learning positions of multiple (academic and social) experiences. The notion of student-athletes as troublemakers is unfounded, nonetheless it gives the false impression that student-athletes are not focused academically (Eagleman, 2011). A professor's other positioning of student-athletes in a certain way can lead to positioning them in a corrective posture (van Langenhove \& Harré, 1999) (as cited in Yoon, 2008, p. 499). For example, the studentathletes found that the professors often used reactive and punitive strategies (lowering students' grades if student-athletes did not follow the professor's direction) in the absence of a planned preventive and culturally relevant educational approach in the classrooms (Van Acker, Grant, \& Henry, 1996). Course instructors should respect, value, and embrace the racial identities, origins, languages, and cultures of student athletes (Weber, 1986).

According to Weidman, Twale, and Stein (2001), students show significant learning outcomes through three core elements (knowledge acquisition, investment, and involvement) in the academic socialization process. Socialization and mentorship by professors are of critical importance for international student-athletes, who need to acquire the skills and abilities necessary to be academically and socially successful. In view of the current student-athletes, some course instructors held stereotypic beliefs and even showed discriminative behaviors toward them. The studentathletes had hoped the professors would become persons they could talk to meaningfully or that they could consult with outside of class. Pratt, Kelly, and Wong (1999) asserted that effective teachers are described as having protective and caring relationships with students. Additionally, they sometimes fulfill the role of a parent, including guiding the intellectual, moral, and personal development of students (Tam, Heng, \& Jiang, 2009).

The student-athletes indicated that they all were assigned to take more online courses rather than classroom-based courses, because student- 
athletes must avoid schedule conflicts between academic and athletic duties. They preferred to take classroom-based courses and saw the benefits of this type of course format, such as an automatic connection because of physical presence and the instructor's ability to interpret students' non-verbal communication and real-time interactions. However, in an online course student-athletes do not have access to those signals and mechanisms and must depend almost exclusively on e-mail communications (Holzweiss, Joyner, Fuller, Henderson, \& Young, 2014). Additionally, online communication often caused misunderstandings, and the academic experiences of the student-athletes were more difficult when their professors failed to respond to their e-mail messages in a timely manner. Studentathletes face a difficult task in regard to creating their own learning that keeps their motivation. It is speculated that there is an advantage in that online courses can offer greater flexibility to student-athletes while allowing them to save time. But, there is a lack of empirical evidence to support that speculation regarding international student-athletes. In this current study, it appears that the on-line courses helped the international student-athletes avoid stereotypical comments and biases toward them from course instructors and fellow students. This is an area in need of further study as well.

Davies and Harré (1990) explained that student-athletes who do not hold power on teams often show self-positioning rather than otherpositioning (e.g., I am not like you as American; not like you). To address such resistance and meet athletic, social, and academic goals and objectives, coaches and athletic staff must understand acculturative stress and the positions of power dynamics of student-athletes. The student-athletes lacked social support and mentors, which was manifested as acculturative stress due to alienation and isolation based on their racial and athletic status. In the current inquiry, acculturative stress might cause student-athletes to have depression, low self-esteem, or academic and athletic difficulties (Brittan, Sy, \& Stokes, 2009). In addition, acculturative stress affects a studentathlete's health and motivation and increases social deviance (Pillay, 2005). International student-athletes are susceptible to acculturative stress due to their status as underrepresented ethnic minorities.

Thoits (1995) and more recently Carter-Farancique, Hart, and Steward (2013) asserted that social integration, emotional social support, and confident relationships were linked to student-athletes' physical and mental health. In this present study, the student-athletes identified athletic 
positions as being integrated physically (dumped into the team without support and mentoring) with their athletic teams, but they were not socially integrated within the team. They desired to receive teammates' support in a way that would help them improve their confidence and form meaningful relationships that would reduce their physical and mental stress.

The student-athletes were less motivated to commit to their athletic teams because they were concerned about potentially losing their scholarships (Sato et al., 2011). They felt their teammates and coaches were not helpful to them, and they did not establish social and peer support systems that helped enhance the quality of their academic and athletic experiences. Further, the international student-athletes felt that racial discrimination is a sensitive yet unavoidable issue to be discussed within the domain of athletic contexts. They believed that their transition into the HBCU campus climate was difficult and challenging. The international student-athletes felt marginalized and even discriminated against by some of the African American student-athletes. These particular student-athletes had positioned the international student-athletes as outsiders infringing on the founding mission and tradition of the HBCU, where cultural communion and Afrocentrism were prominent. This finding is consistent with Sato and colleagues' (2011) previous findings regarding international student-athletes at an HBCU. In addition, the international student-athletes from South Korea were teased about friendship and social patterns by African American student-athletes at the HBCU. In Korean culture, a friendship entails a serious obligation in line with a certain hierarchy whereby friends differ in age, rank, health, experience, and wealth. For example, Korean studentathletes are culturally taught to obey rules and regulations and show respect to older Korean student-athletes (Lee \& Padilla, 2016). Often, junior and senior level Korean student-athletes are regarded as authoritative protectors by new incoming Korean freshman or sophomore student-athletes (Lee \& Padilla, 2016).

Hurtado, Engberg, Ponjuan, and Landreman (2002) found that the more student-athletes were engaged with diverse friends prior to entering college and university, the more likely they were open to and hold diverse viewpoints. The researchers of this current study found that these studentathletes positioned themselves within the self-segregation that occurred in the locker room and practiced among teammates on campus (Beamon, 2014). It seems that the international student-athletes and their teammates did not have beneficial and meaningful contact that brought racial groups 
together. In order to improve racial harmony within athletic teams, coaches and staff should embed self-responsibility and social responsibility training (Hellison, 1995) in athletic team meetings (Andreouli, 2010). Moghaddam (2003) explained that a focus on student-athlete duties (roles and responsibilities) and rights must be well-balanced and embedded in team building and practices that help student-athletes upgrade and sustain their status positions.

The student-athletes were positioned in an under-resourced athletic program, which they credited as a salient factor in influencing their athletic motivation at the HBCU. Nationally, many HBCUs' athletic departments are housed in what are considered low-resource institutions; where the athletic departments spend in the bottom $10 \%$ per capita on their athletes (Charlton, 2011). In 2010, Academic Progress Report (APR) results indicated that more than $52 \%$ of HBCUs in competing Division I received penalties for negative results on the academic and athletic index (Charlton, 2011). The HBCU we studied struggled to develop a positive organizational culture that increases student-athletes' motivation. An organizational culture has three components - organizational support, commitment, and citizenship (Schroeder, 2010).

Organizational support is the belief student-athletes have about how much the department of athletics (including coaches and director) values them. Organizational commitment has two components-affective and normative commitment. Affective commitment is when student-athletes feel they have supportive athletic directors and coaches and a positive athletic environment. Normative commitment is the student-athletes' disposition to be loyal to the HBCU. Organizational citizenship is the behaviors that are above and beyond the call of duty, such as staying late, helping others, and practicing when no one is watching.

In the current study, the student-athletes should have been motivated to contribute their knowledge, skills, and competency to their athletic teams and institutions about the above adverse factors that might have caused negative results (dissatisfaction and a loss of motivation) within the athletic teams.

\section{Study Limitations}

This study has several limitations. First, the participants were purposefully selected from one private co-educational HBCU. Statistically speaking, the findings are therefore not generalizable. From a qualitative 
perspective, however, the reader may consider transferability to the contexts of private or public colleges and universities elsewhere (Leininger, 1994). Second, the sample size was small, and the students had rather diverse backgrounds, experiences, cultures, and languages. Yet, qualitative inquiries, including case studies, typically use small samples, and in the logic of maximum variation sampling the intent is to capture and describe the central themes that cut across a vast array of participant variation in ethnicity (Patton, 2002). Our intention in using this sampling approach was to uncover common themes reflective of a diversity of international studentathletes. A third and fourth limitation was that some participants' native (primary) language was not used in gathering data for this study and the interview guides were not validated in their native languages. English was used for all data collection with each participant. They might not have fully understood some questions or might have been limited in using English to articulate their views about their experiences.

\section{IMPLICATIONS AND CONCLUSIONS}

These international student-athletes struggled to overcome academic, social, and athletic challenges relating to their language differences, athletic responsibilities, stereotypes and discrimination, as well as stressors such as time demands and isolation (Sato \& Hodge, 2009). Although they had difficulty adjusting to the HBCU, they tried to learn how to cope in this particular campus climate. Next, we articulate recommendations that will help support the academic, social, and athletic experiences of international student-athletes. First, faculty members should undergo cultural awareness training (e.g., in academic and social issues such as how to eliminate biases and improve racial diversity in classrooms) so as to help them better understand these particular student-athletes' unique challenges (Sato et al., 2011).

Second, athletic directors, coaches, staff, and administrators need to become more aware of the growing enrollment of diverse student-athletes on American campuses and become more sensitive to the needs of these students in terms of academic and social experiences (Sato \& Hodge, 2009). In collaboration with the office of student academic affairs, academic units, and the diversity office of outreach, mandatory events on cultural, social and academic experiences and seminars should be held to address issues concerning student-athletes' academic and social experiences, 
discrimination, marginalization, and diversity (Sato, Kozub, \& SamalotRivera, 2016). It is also important to institutionalize a commitment to student-athletes' diversity (including internationalism) (Sato, Hodge, \& Eckert, 2017). Athletic departments should include in the promotion and renewal contract process an evaluation of coach and staff activities associated with promoting such diversity. Cross-cultural mentoring (working with coaches, staff, faculty, and senior student-athletes) is one example that should be a meaningful part of formation of students' academic, social, and athletic developments that emphasize more culturally sensitive, responsive, and relevant guidance on campus (Collins, Kamya, \& Tourse, 2001). The student-athletes understand some of the ways of adjusting to the HBCU, they may be able to gain the knowledge and skills of how to cope with particular academic, social, and athletic situations. This type of accountability measure would encourage all student-athletes to engage more regularly in activities of diversity (Hodge \& Wiggins, 2010).

Third, athletic departments need to evaluate definitions of the essential elements of department culture. Schroeder (2010) explained that it was important that all coaches, staff, and student-athletes understand the culture and subcultures about how these elements influence departments' values and the impact of the history and tradition of athletic programs. Adjusting athletic programs to meet student-athletes' needs will undoubtedly result in stronger and more comprehensive athletic programs.

Lastly, international student-athletes should be encouraged to document their sources of academic, social, and athletic stress and their coping responses through journaling techniques. These techniques might enhance self-awareness of students' thoughts and feelings in specific work contexts (Reed \& Giacobbi, 2004). Hill (2001) stated that self-awareness is a critical first step toward identifying specific situations that elicit stressrelated emotions in academic, social, and athletic experiences. This awareness allows international student-athletes to develop problem-solving techniques.

To better support international student-athletes at HBCUs, we encourage athletic departments, coaches, faculty, and all students to respect, value, and embrace the racial identities, origins, languages, and cultures of student-athletes of diversity. This will contribute to a greater appreciation for the richness of diversity and to meaningful academic, athletic (as a competitor or spectator), and social experiences at HBCUs for all students. 


\section{REFERENCES}

Andreouli, E. (2010). Identity, positioning and self-other relations. Papers on Social Representations, 19(1), 14.1-14.13.

Andrews, A., \& Frankel, E. (2010). Inclusive education in Guyana: A call for change. International Journal of Special Education, 25(1), 126 -144.

Barnes, M. (2004). The use of positioning theory in studying student participant in collaborative learning activities. Paper presented at the Annual Meeting of the Australian Association for Research in Education, Melbourne, Australia.

Barrett, M. F., \& Huba, M. E. (1994). Factors related to international undergraduate student adjustment in an American community. College Student Journal, $28,422-435$.

Beamon, K. (2014). Racism and stereotyping on campus: Experiences of African American male student-athletes. The Journal of Negro Education, 83(2), 121-134.

Boeije, H. R. (2010). Analysis in qualitative research. London: Sage.

Brittan, A., Sy, S. R., \& Stokes, J. (2009). Mentoring: Implications for African American college students. Western Journal of Black Studies, 87-97.

Carter-Francique, A., Hart, A., \& Steward, A. (2013). Black college athletes' perceptions of academic success and the role of social support. Journal of Intercollegiate Sport, 6, 231-246.

Charlton, R. (2011). The role of policy, rituals, and language in shaping an academically focused culture in HBCU athletics. Journal of Issues in Intercollegiate Athletics, 4, 120 - 148.

Collins, P. M., Kamya, H. A., \& Tourse, R. W. (2001). Questions of racial diversity and mentorship: An empirical exploration. Social Work, 42(2), 145-152.

Connell, C. (2007). For international student-athletes, a longer obstacle course. International Education, 16(5), 58-62.

Davies, B. \& Harré, R. (1990). 'Positioning: the discursive production of selves'. Journal for the Theory of Social Behaviour, 20, 43-64.

Eagleman, D. M. (2011). Incognito: The secret lives of the brain. New York: Random House.

Harré, R., \& van Langenhove, L. (1999). The dynamics of social episodes. In R. Harré, \& L. van Lagenhove (Eds.), Positioning theory: Moral contexts of intentional action (pp. 14-31). Malden, MA: Blackwell.

Harré, R., \& Moghaddam, F. M. (Eds.). (2003). The self and others: Positioning individuals and groups in personal, political and cultural contexts. Westport, CT: Praeger.

Hayes, L. H. \& Lin, H. R. (1994). Coming to American: developing social support systems for international students. Journal of Multicultural counseling and Development, 22, 7-16. 
Hellison, D. (1995). Teaching responsibility through physical activity. Champaign, IL: Human Kinetics.

Hermans, H. J. M. (2001). The dialogical self: Toward a theory of personal and cultural positioning. Culture \& Psychology, 7(3), 243-281.

Hill. K. L. (2001). Frameworks for Sport Psychologists: Enhancing Sport performance. Champaign, IL: Human Kinetics.

Hodge, S. R., \& Wiggins, D. K. (2010). The African American experience in physical education and kinesiology: Plight, pitfalls, and possibilities. Quest, 62, 35-60.

Hollway, W. (1984). Gender difference and the production of subjectivity. In J. Henriques, W. Hollway, C. Urwin, C. Venn, \& V. Walkerdine (Eds.), Changing the subject: Psychology, social regulation and subjectivity (pp. 227-263). London, England: Methuen.

Holzweiss, P., Joyner, S. A., Fuller, M. A., Henderson, S., \& Young, R. (2014). Online graduate students' perceptions of best learning experiences. Distance Education, 35(3), 311-323.

Hurtado, S., Engberg, M.,E., Ponjuan, L., \& Landreman, L. (2002). Students' precollege preparation for participation in a diverse democracy. Research in Higher Education, 43(2), 163-186.

Jones, R. A. (1997). Direct perception and symbol forming in positioning. Journal for the Theory of Social Behaviour, 29, 37-58.

Kayi-Aydar, H. (2013). Social positioning, participation, and second language learning; Talkative students in academic ESL classroom. TESOL Quarterly, 48(4), 686-714.

Lee, D. S., \& Padilla, A. M. (2016). Predicting South Korean university students' happiness through social support and efficacy beliefs. International Journal for the Advancement of Counseling, 38, 48-60.

Leininger, M. (1994). Evaluation criteria and critique of qualitative research studies.In J.M. Morse (Ed.), Critical issues in qualitative research methods (pp. 95-115). Thousand Oaks, CA: Sage.

Lincoln, Y. S., \& Guba, E. G. (1985). Naturalistic Inquiry. Newbury Park, CA: Sage.

McVee, M.B., Baldassarre, M., \& Bailey, N. (2004). Positioning theory as lens to explore teachers' beliefs about literacy and culture. C. M. Fairbanks, J. Worthy, B. Maloch, J. V. Hoffman, \& D. L. Schallert (Eds.). 53rd National Reading Conference Yearbook (pp. 281-295). Oak Creek, WI: National Reading Conference.

Meho, L. I. (2006). E-mail interviews in qualitative research: A methodological discussion. Journal of the American Society for Information Science and Technology, 57(10), 1284-1295.

Merriam, S. B. (1998). Qualitative Research and Case Study Applications in Education. CA, San Francisco, Jossey-Bass Publisher. 
Moghaddam, F. M. (2003). Interobjectivity and culture. Culture \& Psychology, 9(3), 221-232.

National Collegiate Athletic Association. (2007). Division II student-athlete experience evaluations. Retrieved from www.ncaa.org/library/ membership/d2_sa_experience_evaluation/2006_d2_s-a_experience_ evaluation.pdf.

Parr, G., Bradley, L., \& Bingi, R. (1992). Concerns and feelings of international students. Journal of College Student Development, 33, 20-25.

Pratt, D. D., Kelly, M., \& Wong, W. S. S. (1999). Chinese conceptions of "effective teaching" in Hog Kong: Towards culturally sensitive evaluation of teaching. International Journal of Lifelong Education, 18, 241-258.

Patton, M. (2002). Qualitative research and evaluation methods (3rd ed.) Thousand Oaks, CA: Sage.

Pillay, Y. (2005). Racial identity as a predictor of the psychological health of African American students at a predominantly White university. Journal of Black Psychology, 31(1), 46-66.

Reed, S., \& Giacobbi, P. R. Jr. (2004). The stress and coping responses of certified graduate athletic training students. Journal of Athletic Training, 39(2), 193-200.

Ridinger, L. L., \& Pastore, D. (2000). International student-athlete adjustment to college: A preliminary analysis. NACADA Journal, 20(1), 33-41.

Sato, T., \& Hodge, S. R. (2009). Asian international doctoral students' experiences at two American University: assimilation, accommodation, and resistance. Journal of Diversity in Higher Education, 2(3), 136-148.

Sato, T., \& Hodge, S. R. (2016). Asian international graduate students' academic and social experiences in American higher education. In K. Bista, \& C. Foster (Ed.), Exploring the social and academic experiences of international students in higher education institutions (pp. 1-19). Hershey, PA: IGI Global.

Sato, T., Hodge, S. R., \& Burge-Hall, V. (2011). International student-athletes' academic, athletic, and social experiences at a historically Black university in America. Journal for the Study of Sports and Athletes in Education, $5(1), 45-72$.

Sato, T., Hodge, S. R., \& Eckert, K. (2017). Experiences of Black Student-Athletes on a Predominantly White University Campus. Journal for Study of Sport and Athletes in Education, 1-21. http://dx.doi.org/10.1080/ 19357397.2017.1316890

Sato, T., Kozub, F. M., \& Samalot-Rivera, A. (2016). Students' academic and social transition to new graduate programs in physical education. Multicultural Learning and Teaching, 1-20. doi:10.1515/mlt-2015-0018 
Schroeder, P. J. (2010). A model for assessing organizational culture in intercollegiate athletic departments. Journal of Issues in Intercollegiate Athletics, 3, 98-118.

Shuy, R. W. (2002). In-person versus telephone interviews. In J. F. Gubruim \& J. A. Holstein (2002). Handbook of interview research: Context and method (pp. 537-555). Thousand Oaks, CA: Sage.

Snyder, T. D., Dillow, S. A., \& Hoffman, C. M. (2009). Digest of education statistics 2008 (NCES 2009_020). Washington, DC: National Center for Education Statistics, U.S. Department of Education. Retrieved from http://nces.ed.gov/pubsearch

Tam, K., Heng, M., \& Jiang, G. (2009). What undergraduates in China say about their professors' teaching. Teaching in Higher Education, 14, 147-159.

Thoits, P. A. (1995). Stress, coping, and social support processes: Where are we? What next? Journal of Health and Social Behavior, 35, 53-79.

Van Acker, R., Grant, S. G., \& Henry, D. (1996). Teacher and student behavior as a function of risk for aggression. Education and Treatment of Children, 19, 316-334.

Vanassche E., \& Kelchtermans G. (2014). Teacher educators' professionalism in practice: Positioning theory and personal interpretative framework. Teaching and Teacher Education, 44, 117-127.

van Langenhove, L. \& Harré, R. (1999). Introducing positioning theory. In R. Harré, \& L.van Lagenhove (Eds.), Positioning theory: Moral contexts of intentional action (pp. 14-31). Malden, MA: Blackwell.

Varela, C., \& Harré, R. (1996). Conflicting varieties of realism: Casual powers and the problems of social structure. Journal for the Theory of Social Behavior, $26,313-325$.

Wan, G. (2001). The learning experience of Chinese students in American universities: A cross-cultural perspective. College Student Journal, 12(1), 106-118.

Weber, M. (1986). Domination by economic power and by authority. In S. Lukes (Ed.), Power (pp.28-36). New York: New York University Press.

Weidman, J. C., Twale, D. J., \& Stein, E. L. (2001). Socialization of graduate and professional students in higher education: A perilous passage? San Francisco, CA: Jossey-Bass.

Wilson, V. R. (2007). The effect of attending an HBCU on persistence and graduation outcomes of African-American college students. The Review of Black Political Economy, 34, 11-52.

Yin, R. K. (2003). Case study research design and methods (3rd ed.). Thousand Oaks, CA: Sage.

Yoon, B. (2008). Uninvited guests: The influence of teachers' roles and pedagogies on the positioning of English language learners in the regular classroom. American Educational Research Journal, 45, 495-522. 
TAKAHIRO SATO, Ph.D. CAPE, is an Associate Professor in School of Teaching, Learning, \& Curriculum Studies at Kent State University, Kent, OH. He served as Health and Physical Education program coordinator at Hampton University (2007-2010). His scholarship and research focuses on multicultural physical education, inclusion in sport, and diversity in higher education. E-mail: tsato@kent.edu

SAMUEL R. HODGE, Ph.D., is a Professor in Department of Human Sciences at The Ohio State University, Columbus, $\mathrm{OH}$. His scholarship and research focuses on social justice pedagogies, diversity, and disability in physical education. E-mail: hodge.14@osu.edu

KEVIN ECKERT, MA., is an Assistant Professor of Physical Education Teacher Education (PETE) at Kent State University. He was an assistant coach of women's basketball teams at Indiana University, Bowling Green State University, and State of University of New York at Buffalo. His areas of expertise are working with diverse populations, including the people of color. He received his MA in Athletic Administration from Ohio University and his MA in PETE at Kent State University. E-mail: keckert5@kent.edu 